\title{
La tierra de Edom y Moab: una colección de arte nabateo
}

Dra. María LuZ MANGAdo Alonso

RESUMEN: Los nabateos constituyen un antiguo pueblo cuya actividad se desarrolló especialmente al Sur y al Este de Palestina. La capital la mayor parte del tiempo fue Petra, que está situada a $80 \mathrm{~km}$ al sudeste del Mar Muerto. Su época de mayor esplendor abarca del siglo IV a. C. al I d. C. La presencia de obras nabateas en las colecciones de Próximo Oriente Antiguo es prácticamente nula. La colección de obras que aquí exponemos se divide en monedas, recipientes, lucernas, dioses y joyería. Todas las obras proceden de la ciudad de Petra, que nos permite una aproximación a esta época histórica. PALABRAS CLAVES: Obras nabateas

ABSTRACT: The Nabataeans are an ancient people whose activities are developed especially to the south and east of Palestine. The capital most of the time was Petra, which is located $80 \mathrm{~km}$ southeast of the Dead Sea. Its heyday comprised of fourth century b. C. when I a. C. The presence of Nabataean works in the collections of Ancient Near East is limited. The collection of works that we expose here is divided into coins, vessels, lamps, gods and jewelry. All the works come from the city of Petra, which allows us to approach this period. KEY WORDS: Nabataean pieces

\section{Los nabateos y la historia bíblica}

Los nabateos constituyen un antiguo pueblo cuya actividad se desarrolló especialmente al Sur y al Este de Palestina. La capital la mayor parte del tiempo fue Petra, que está situada a $80 \mathrm{~km}$ al sudeste del Mar Muerto. Su época de mayor esplendor abarca del siglo IV a. C. al I d. C. Era una ciudad de comerciantes caravaneros de mercaderes procedentes de Arabia, India, y Mar Rojo. Los nabateos se identifican con la tribu de Nébáyót, de 
ahí su relación con Ismael ${ }^{1}$. Pertenecían al grupo de los arameos. En este tiempo eran eminentemente nómadas y la ley vigente entre ellos les prohibía sembrar trigo, plantar árboles o construir casas.

Hacia 170 a. C. los reyes nabateos entran en la historia bíblica. Aretas I persiguió a Jasón forzando su huida a Europa ${ }^{2}$. Por este tiempo se rompió la antigua amistad con los judíos, y así los nabateos que ayudaron en más de una ocasión a los macabeos ${ }^{3}$, se vieron atacados por rey judío Alejandro Janneo, que les arrebató algunas urbes. Aretas II se puso del lado de Gaza en su discordia con aquellos. Gracias a la ayuda de los nabateos pudo resistir esta ciudad el ataque de sus enemigos.

La tierra de Moab estaba colonizada, en cierto modo, por los nabateos. Alejandro Janneo consiguió someterla a tributo, sin que el rey nabateo Obodas I pudiese impedirlo. Por su parte los romanos continuaron sus incursiones por el territorio nabateo. Más tarde Alejandro Janneo fue derrotado cerca de Garada en la Gaulanítide gracias al dominio de esas rutas comerciales que el rey Obodas I aún poseía.

Su sucesor Aretas III gobernó en Damasco hacia el año 85 a. C. Esta injerencia de los nabateos era mal vista por Pompeyo; pero ellos se mantenían seguros gracias al control y dominio de las rutas del Este. El general romano envió contra la capital de los nabateos a Scaruz que llegó hasta Petra, pero sólo consiguió 300 talentos que el rey nabateo pagó gustosamente con tal de verse libre de la poco grata presencia romana. Más tarde (55 a. C.), Gabinus intentó obtener algún botín de los nabateos antes de volverse a Roma, pero lo más que consiguió fue la liberación de los partos exiliados.

El rey Malicos (60 - 30 a. C.) tuvo que pagar al legado romano Ventidius una fuerte suma en concepto de tributo. Este mismo rey nabateo entabló lucha contra el hijo del idumeo Antípatro que tanto favor gozaba en la corte judía de los asmoneos. Las primeras refriegas con el que sería más tarde Herodes el Grande tienen lugar al Norte del río Yarmuk en Diáspolis y Canata. Después de una primera victoria judía, Herodes es vencido por los nabateos, pero pronto tomó la revancha, junto a Filadelfia, donde aquellos sufrieron una fuerte derrota.

Con Aretas IV (9 a. C. - 40 d. C.) el reino alcanza su máximo esplendor. Supo atraerse el favor de Roma poniendo a disposición de Varus buen

\footnotetext{
${ }^{1}$ Cfr. Gen 25,13;28,9; 36,3; 1 Par 1,29

22 Macabeos 5,8

${ }^{3} 1$ Macabeos 5,25; 9,35
} 
contingente de hombres contra una sedición de los judíos. La enemistad con el país vecino aumentó cuando Herodes Antipas, tetrarca de Galilea, repudió a la hija del rey Aretas IV, uniéndose con Herodias la mujer de su hermano. Este fue el verdadero motivo de la guerra, aunque se justificara con cuestiones fronterizas.

Tiberio se puso de parte de los judíos y ordenó que, vivo o muerto, Aretas fuese llevado a Roma, pero muerto el emperador, Vitelio, legado de Siria, no consiguió apresar al monarca que permaneció en Petra, sin olvidar sus dominios del Norte en la región damascena. En tiempo de Calígula (37 - 41) estuvo representado en Damasco por un etnarca que veló por los intereses del pueblo. En este periodo ocurrieron los hechos a que se refiere San Pedro ${ }^{4}$. Los sucesores de Aretas IV perdieron el control de Damasco en tiempos del emperador Nerón.

Rabel II (71 - 106) fue el último rey nabateo. La unificación que se había realizado alrededor de este reino por la incorporación del último territorio herodiano del norte de Yarmuk, debería proseguir normalmente con la anexión de la Arabia nabatea al Imperio Romano.

En tiempos del emperador Trajano, el legado de Siria ocupó el país (105 d. C.), dominando las localidades de Bosra y Petra. Al año siguiente el territorio nabateo quedó convertido en provincia romana administrada por un legado, con la III Legión Cirenaica a su mando. No obstante, Petra seguiría conservando su prestigio y en más de una ocasión sería la residencia del legado romano.

Los nabateos conservaron la peculiaridad de su dialecto por mucho tiempo, aunque poco a poco se fueron arabizando hasta el punto de que los romanos los identificaban con los árabes. Así Estrabón ${ }^{5}$ habla de Petra como la ciudad de los árabes llamados nabateos.

El aumento de población y el cambio de circunstancias históricas fueron convirtiendo a los nabateos de nómadas en pacíficos agricultores, que se agruparon en pueblos y ciudades. Existían numerosas vías de comunicación que los ponían en contacto entre sí, mientras que una red de fortalezas y torres de guardia les protegían de posibles expediciones enemigas.

Las recientes excavaciones arqueológicas han mostrado hasta qué punto gozaban de una gran organización. No se limitaron a defenderse, sino que también cultivaron con éxito diversas artes e industrias, especialmente la artesanía del cuero, vidrio y cerámica. Su estilo muy original, permite al

\footnotetext{
42 Cor 11,32

${ }^{5} \mathrm{XVI}, 4,18$
} 
arqueólogo distinguirlo con facilidad. Bajo la influencia helenística cultivaron también la escultura y la arquitectura. En esta serie de obras que presentamos exponemos una presentación de este legado.

Trasformado el reino nabateo en región fronteriza, habitada por destacamentos militares de procedencia y origen diverso, fue decayendo paulatinamente su civilización. El territorio nabateo se dividió entre la gente del Sur, reagrupada alrededor de Petra, y las del Norte, en torno a Palmira. La ciudad hasta el siglo V y VI tuvo especial relevancia: grupos de pequeñas comunidades cristianas construyeron nuevas iglesias de hermosos mosaicos.

\section{La colección nabatea}

La presencia de obras nabateas en las colecciones de Próximo Oriente Antiguo es prácticamente nula. La ausencia de estudios en esta área limita de la misma forma el conocimiento de una de los lugares más extraordinarios de la Arqueología. Las campañas de excavación que en estos años se vienen sucediendo sin duda van creando un mayor conocimiento de la esta cultura.

La colección consta de una serie obras de gran interés que agrupan en monedas, recipientes, lucernas, dioses y joyería. Todas las piezas proceden de la ciudad de Petra.

\section{$M O N E D A S^{6}$}

-Moneda Nabatea (N. Inv. 2-1); Material: cobre; Datación: s. IV-V d. C.; Diámetro: $4 \mathrm{~cm}$.

\footnotetext{
${ }^{6}$ Bowsher, J.M.C., 1990. Early Nabataean Coinage, ARAM 2:1-2, 1990,pp. 221-228. Hill, G.F., A Catalogue of the Greek Coins in the British Museum - Arabia, Mesopotamia and Persia, 1922, pp. xi-xxii, 1-13, 314, pl. I-II, XLIX. (Reprinted 1965 by Forni). Meshorer, Y., Nabatean Coins, Qedem Monographs 3, Hebrew University of Jerusalem. Meshorer, Y., SNG American Numismatic Society Part 6 Palestine - South Arabia, New York.Plant, R., The Coinage of the Nabataeans, Seaby Coin and Medal Bulletin, March 1979, pp. 81-84. Robinson, E.S.G., Coins from Petra etc., Numismatic Chronicle 1936, pp. 288-291, pl. XVII. SchmittKorte, K. and Cowell, M., Nabatean Coinage - Part I. The Silver Content Measured by X-ray Fluorescence Analysis, Numismatic Chronicle, Vol. 149, 1989, pp. 33-58, pl. 11-17.

Schmitt-Korte, K., Nabatean Coinage - Part II. New Coin Types and Variants, Numismatic Chronicle, Vol. 150, 1990, pp. 105-133, pl. 10-15. Schmitt- Korte, K. and Price, M., Nabatean Coinage - Part III. The Nabatean Monetary System, Numismatic Chronicle, Vol. 154, 1994, pp. 67-131, pl. 10-12.
} 
En el anverso se representa la imagen de un patriarca bizantino con las inscripción ANNO, XII y un serie de signos ilegibles; en el reverso una $\mathrm{M}$ y una serie de signos ANNO XII.

-Monedas Nabatea (N. Inv. 2-2). Material: plata (n. inv.2-2); Datación: siglo IV a. C.; Diámetro: $5 \mathrm{~cm}$.

En ambas caras de la moneda se encuentra la imagen del templo de Isis, excavado en la roca de Petra situado al final del desfiladero en la entrada de la ciudad. Se diferencia las dos alturas y los pilares corridos de la fachada.

-Monedas Nabateas (N. Inv. 2-3;2-4). Material: 2-3 plata;2-4 Oro; siglo IV a. C.; Diámetro $4 \mathrm{~cm}$.

En el anverso la efigie de Alejandro Magno de perfil rodeado de dos delfines; en el reverso una auriga tirada por cuatro caballos. En la parte inferior se representa un ánfora entre un disco y la cabeza de un equino.

-Moneda Nabatea (N. Inv.2-5). Material: oro; Epoca romana; Diámetro $2 \mathrm{~cm}$;

En el anverso la efigie de Siverusavs Partmax y el reverso Apolo con la inscripción Apolonin Isancto

-Moneda nabatea (N. Inv. 2-6). Material:cobre; Epoca Aretas II 11096 a. C.; Diámetro $1 \mathrm{~cm}$;

En el anverso la efigie de un personaje de perfil con una inscripción ilegible; en el reverso la imagen de un Niké, diosa de la victoria con inscripción griega desgastada.

-Moneda nabatea (N. Inv. 2-7).Material: bronce; Datación: S. VI-I a. C.; Diámetro: $1 \mathrm{~cm}$.

En el anverso está desgastada y en el reverso aparece una palmera.

-Moneda Nabatea (N. Inv. 2-8). Material Cobre: Datación: Epoca griega;Diámetro: $1 \mathrm{~cm}$.

En el anverso la imagen quizá de un carcaj con inscripción griega y en el reverso parte de una inscripción griega ilegible.

-Moneda Nabatea (N. inv. 2-9). Material: Cobre; Datación: Época griega; Diámetro: $1 \mathrm{~cm}$.

En el anverso y reverso la efigie de un personaje laureado

-Moneda Nabatea (N. inv.2-10).Material: Plata; Datación: Época romana; Diámetro $2,5 \mathrm{~cm}$.

En el anverso la imagen de un emperador romano y la inscripción en parte perdida IMPIRANORUC GCCERDA $(i)$ y en el reverso una auriga tirada por un caballo. 
-Moneda nabatea (N. Inv 2-11). Material: Oro; Datación: Epoca griega; Diámetro $3 \mathrm{~cm}$.

En el anverso aparece un busto de perfil, y en el reverso la imagen de una diosa, quizá Afrodita con la inscripción griega en parte perdida AETAELE

-Moneda Nabatea (N. Inv. 2-12).Material: Oro; Datación: s. IV-II a. C.; Diámetro 2,5 cm.

En el anverso hay dos personajes con el rostro de perfil y en el reverso una auriga tirada por un caballo.

-Moneda Nabatea (N. Inv. 2-13).Material: Cobre; Datación: S. IV-VI d. C. Diámetro $3 \mathrm{~cm}$.

En el anverso el patriarca o emperador bizantino sosteniendo la cruz con una inscripción CSPAVS; en el reverso una M surmontada por una Cruz con letras griegas.

-Moneda nabatea (N. Inv. 2-14). Material: Oro; Datación: s. IV- II d. C. Diámetro $2,5 \mathrm{~cm}$.

En el anverso aparece el rostro de dos personajes y en el reverso una auriga tirada por caballos.

-Moneda nabatea (N. Inv. 2-15). Material: Bronce; Datación: Época romana: Diámetro $2,2 \mathrm{~cm}$.

En el anverso la efigie de un personaje de perfil con una inscripción griega IMPERO BVSPEAUG, y el reverso un individuo apoyado en un tronco con la inscripción MP PORAB3RI-O

-Moneda nabatea (N. Inv. 2-16). Material: Bronce; Datación: Época romana; Diámetro 2,2 cm.

En el anverso la efigie de un personaje de perfil con la inscripción IMPERATORE CONSTANTINO PTE SOETE; el reverso CENEO

-Moneda nabatea (N. Inv 2-17). Material: Bronce; Datación: S. IV a. C.- II d. C.; Medidas: $1 \mathrm{~cm}$.

En el anverso la efigie de un personaje de perfil con inscripción NRES; en el reverso aparece una gacela saltando bajo dos estrellas.

-Moneda nabatea (N. Inv. 2-18). Material: Bronce; Datación: Aretas IV a. 9. A. C.- ; Medidas: $1 \mathrm{~cm}$.

En el anverso el rostro de Aretas IV y en el reverso una laureada rodea dos cornucopias con una inscripción en arameo. Este tipo de monedas se empleo en tiempos del nacimiento de Jesús, por Fesael (año 9 a. C,), hijo de Aretas IV 
-Moneda Nabatea (N. Inv. 2-29). Material: Plata; Datación: Época romana; Medidas: $2,5 \mathrm{~cm}$.

En el anverso la efigie de emperador romano con la inscripción IMPERO PRO BUS PE AUG; en el reverso un guerreo delante de un caballo con la leyenda PROGRESSUS

-Moneda Nabatea (N. Inv. 2-30). Material: Oro; Datación: siglo IV a. C.; Medidas: $2 \mathrm{~cm}$.

En el anverso el rostro de Alejandro Magno de perfil con el cuerno de la abundancia como pendientes y el reverso un león bajo una estrella.

\section{RECIPIENTES}

-Ungüentario (N. Inv. 2-25). Material: Cerámica; Datación (s. IV-II a. C.); Medidas: altura $10 \mathrm{~cm}$; anchura $3 \mathrm{~cm}$.

Ungüentario en forma de botella hecha a torno con cuello alargado, y base circular y ligeramente puntiaguda. Servía para contener esencias o perfume.

-Jarra (N. Inv. 2-28). Material: cerámica; Datación: s. IV-II a. C.; Medidas: Altura $13 \mathrm{~cm}$; anchura $6 \mathrm{~cm}$.;

Jarra realizada a torno con pie circular, panza abombada e irregular; posee un cuello largo y estrecho con un asa lateral. El borde es redondeado y posee un pitón o protuberancia.

-Taza (No. Inv. 2-28). Material: cerámica; Datación: S. IV-II a. C.; Medidas: $11 \mathrm{~cm}$. largo ; anchura $6,5 \mathrm{~cm}$;

Taza de cerámica más ancha en la base que en el borde, con un asa lateral. El borde es sencillo, y posee restos de calcárea en su interior.

-Fragmentos de cerámica (N. Inv. 2-20) Datación: S. IV a.-C.- II d. C. Medidas: entre 7 y $11 \mathrm{~cm}$.

Doce fragmentos de cerámica cocida perteneciente a recipientes, ungüentarios, lucernas nabateos y a un colador. Destaca un fragmento de cerámica muy fina romana, tipo terra sigilata decorada con motivos geométricos y vegetales.

\section{LUCERNAS ${ }^{7}$}

-Lucerna (N. Inv. 2-21). Material: cerámica realizada a molde; Datación: s. IV a. C.- S. II d. C.; medidas: $5 \mathrm{~cm}$. anchura; longitud $7 \mathrm{~cm}$.

\footnotetext{
${ }^{7}$ Se fabricaron con muy diferentes formas, pero básicamente estaban compuestas por un depósito para el aceite (infundibulum), un pico (mixus) que contiene un orificio, deno-
} $\therefore$ 
Lucerna sección bicónica, boquilla de punta redonda unida al cuerpo por un canalillo poco pronunciado Cuerpo convexo saliente; alrededor del orificio de alimentación se decora con líneas verticales paralelas. Disco incipiente decorado con una moldura. Base plana anular. Dentro de la lucerna se encuentra el tapón del orificio central. Cubierta de engobe rojizo. Se uso en la vida cotidiana, ceremonias religiosas y ritos funerarios.

-Lucerna (N.inv 2-23) Material: cerámica realizada a molde. Datación: s. II C.-s. IV d. C.; medidas $9 \mathrm{~cm}$. de largo; ancho $5 \mathrm{~cm}$.

Lucerna tipo disco sin decoración de recipiente aplastado con orificio de alimentación muy pequeño en el centro del disco que es amplio y algo hundido. Base plana anular. El pico es puntiagudo y sobresale del disco, con restos negruzcos de la combustión. Un canal más amplio une el disco con el pico. Carece de decoración y posee un color grisáceo.

-Lucerna (N. inv. 2-24) Material: cerámica realizada a molde. Datación: s. II C.-s. IV d. C.; medidas $10 \mathrm{~cm}$. de anchura; anchura $6 \mathrm{~cm}$.

Lucerna de perfil bicónico, y base plana anular. De color rojizo con engobe. Orificio de alimentación amplio con aro o moldura. Decoración en la superficie del disco por un pez a cada lado entre molduras dispuestas en forma radial, que se extienden hasta el puente. Asa engastada de forma cónica.

\section{DIOSES}

-Dios o genio nabateo (N. inv. 2-38). Material: cerámica; Medidas: Datación: S. IV-II a. C.;

Cabeza en terracotta que representa una divinidad o genio, quizá Hermes con los mechones del cabello muy marcados, el ceño fruncido y las orejas puntigaudas. Posee un orificio en el ojo y en el lóbulo de la oreja

\section{JOYERIA}

-Anillo nabateo (N. inv. 2-26). Material: Oro y vidrio; Datación: S. IVII a. C.; Medidas: Anchura $2 \mathrm{~cm}$; altura $1,8 \mathrm{~cm}$.

Anillo con montura de oro y engaste en piedra de vidrio de color rojo.

minado agujero de luz, donde se introducía la mecha que al arder lentamente era la encargada de emitir la luz, y el agujero de alimentación en la parte superior que favorecía la combustión. 
-Anillo nabateo (N. inv. 2-27).Material: Oro y carneola; Datación: S. IV- II a. C.; Medidas: Anchura 2,5 cm.; altura $2 \mathrm{~cm}$.

Anillo con montura de oro y engaste en piedra carneola de color naranja

-Cuenta de collar (N. Inv 2-32). Material: piedra semipreciosa, ágata y pasta vidriada; Datación: s. IV-II a. C. Medidas: 7,5 cm. long,

Cuenta de collar ovalada, hecha de pasta vidriada, Está decorada con tres franjas de color negro que alternan con otras tres doradas, ornamentadas a su vez, con una serpiente y un loto verde. Es posible que formarse parte del collar de un príncipe.

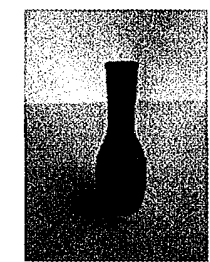

Ungüentario nabateo N. ${ }^{\circ} 2-25$

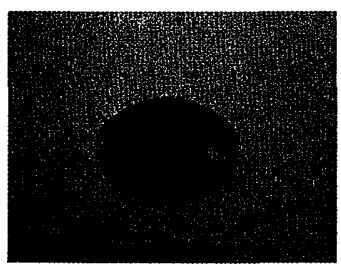

Cuenta de collar N. ${ }^{\circ} 2-32$

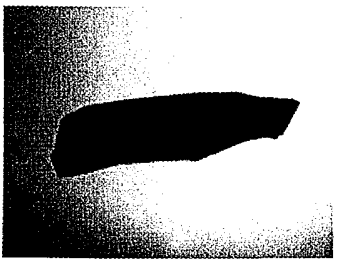

Fragmentos de cerámica nabatea $\mathrm{N} .{ }^{\circ} 2-20(1)$

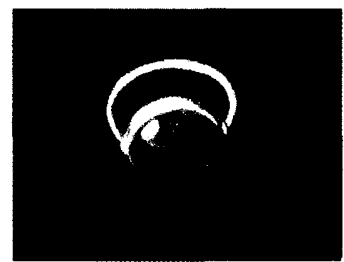

Anillo nabateo

N. ${ }^{\circ} 2-26$

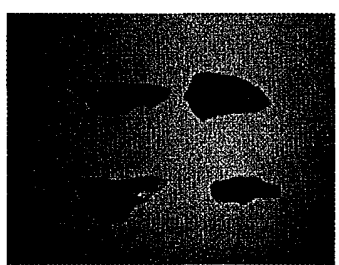

Fragmentos de cristal

N. ${ }^{\circ} 2-19$

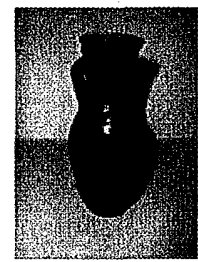

Jarra nabatea N. ${ }^{\circ} 2-28$

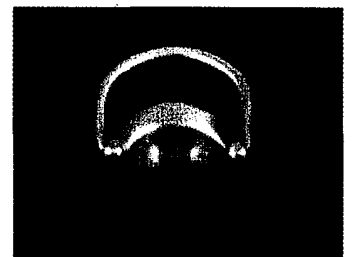

Anillo nabateo N. ${ }^{\circ} 2-27$

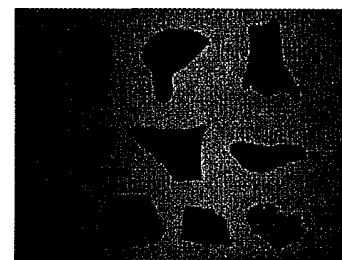

Fragmentos de cerámica nabatea N. ${ }^{\circ} 2-20$

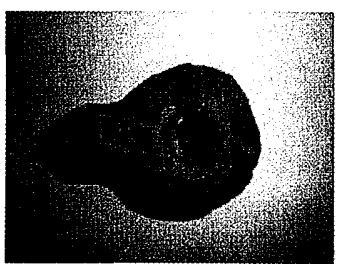

Lucerna N. ${ }^{\circ}$ 2-21 


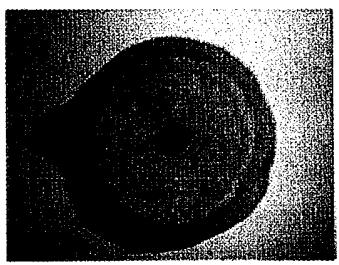

Lucerna

N. ${ }^{\circ} 2-23$

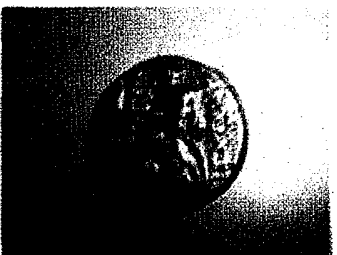

Moneda nabatea

N. ${ }^{\circ} 2-11(1)$

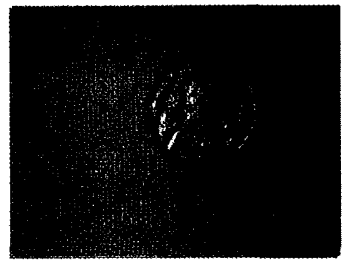

Moneda nabatea N. ${ }^{\circ} 2-1$

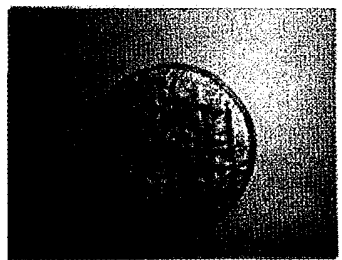

Moneda nabatea N. ${ }^{\circ} 2-2(1)$

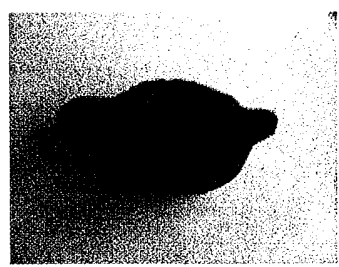

Lucerna

N. ${ }^{\circ} 2-24$

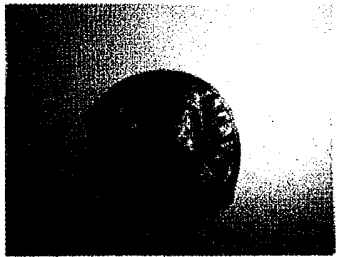

Moneda nabatea N. ${ }^{\circ} 2-13$

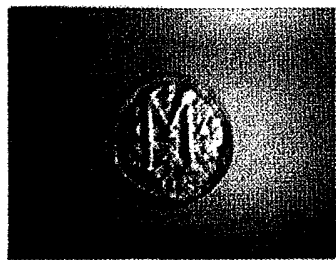

Moneda nabatea N. ${ }^{\circ} 2-1(1)$

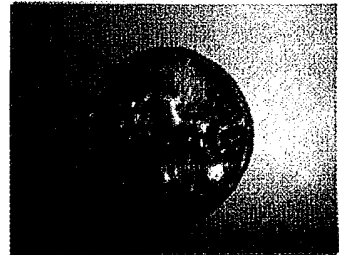

Moneda nabatea N. ${ }^{\circ} 2-3(1)$

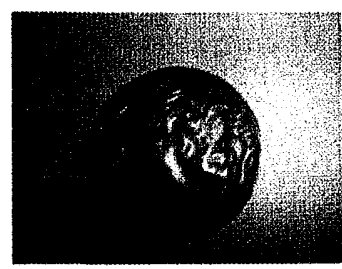

Moneda nabatea N. ${ }^{\circ} 2-3$

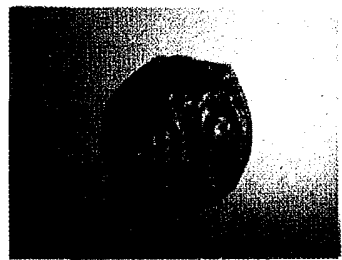

Moneda nabatea N. ${ }^{\circ} 2-13(1)$

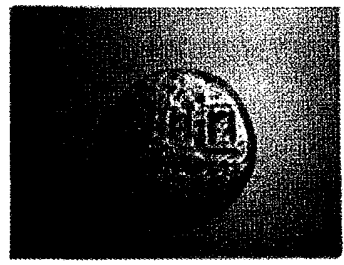

Moneda nabatea N. ${ }^{\circ} 2-2$

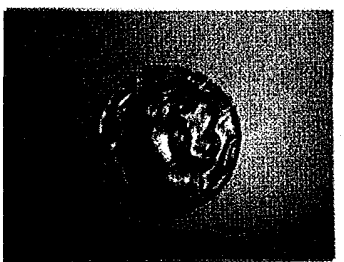

Moneda nabatea N. ${ }^{\circ} 2-4$ 


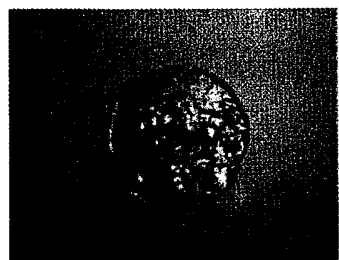

Moneda nabatea N. ${ }^{\circ} 2-4(1)$

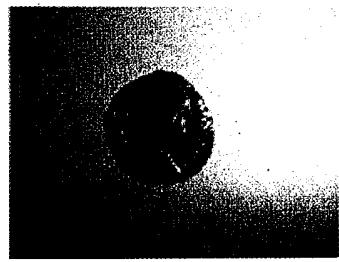

Moneda nabatea

N. ${ }^{\circ} 2-6$

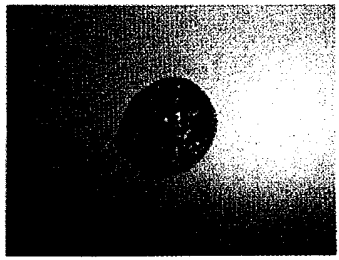

Moneda nabatea N. ${ }^{\circ}$ 2-7 (1)

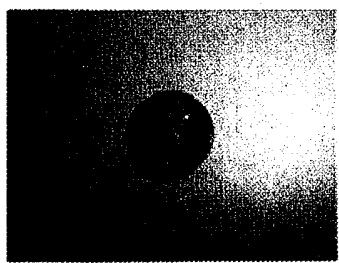

Moneda nabatea

N. ${ }^{\circ} 2-9$

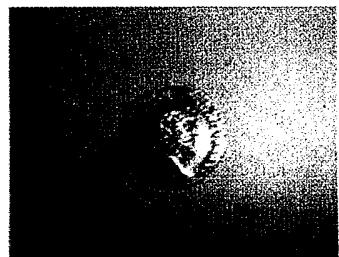

Moneda nabatea

N. ${ }^{\circ} 2-5$

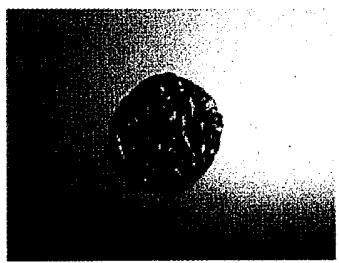

Moneda nabatea

N. ${ }^{\circ} 2-6(1)$

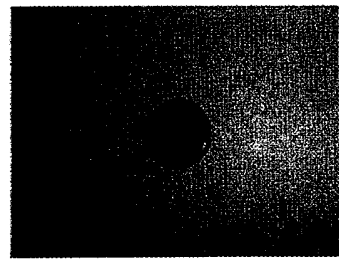

Moneda nabatea

N. ${ }^{\circ} 2-8$

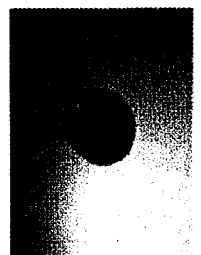

Moneda nabatea N. ${ }^{\circ} 2-9(1)$

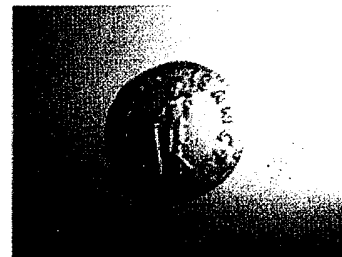

Moneda nabatea

N. ${ }^{\circ} 2-5$ (1)

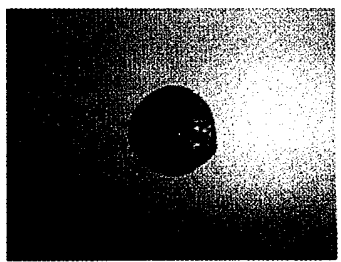

Moneda nabatea

N. ${ }^{\circ} 2-7$

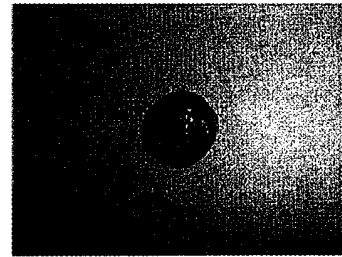

Moneda nabatea N. ${ }^{\circ} 2-8(1)$

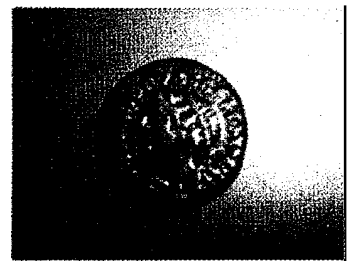

Moneda nabatea

N. ${ }^{\circ} 2-10$ 


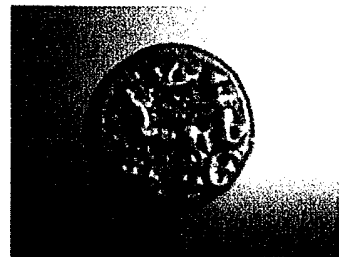

Moneda nabatea N. ${ }^{\circ}$ 2-10 (1)

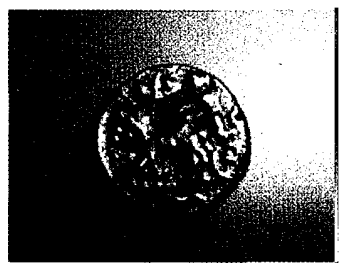

Moneda nabatea N. ${ }^{\circ} 2-12(1)$

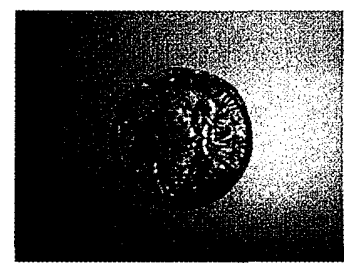

Moneda nabatea N. ${ }^{\circ} 2-15$

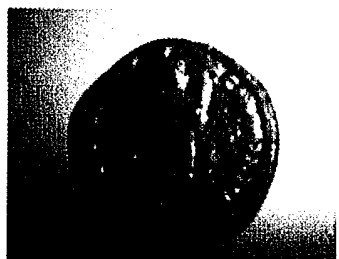

Moneda nabatea N. ${ }^{\circ} 2-16(1)$

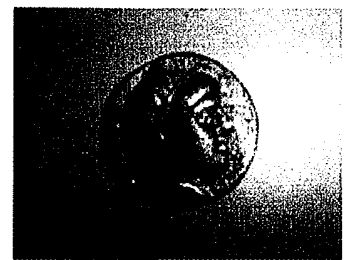

Moneda nabatea

N. ${ }^{\circ} 2-11$

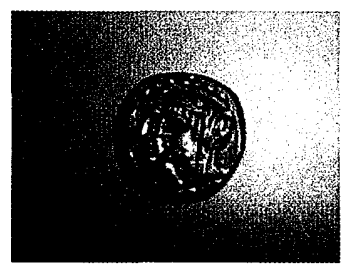

Moneda nabatea N. ${ }^{\circ} 2-14$

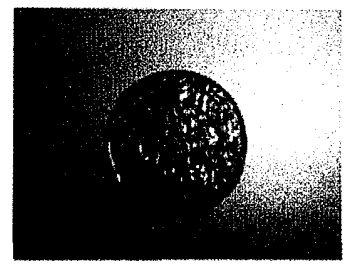

Moneda nabatea N. ${ }^{\circ} 2-15$ (1)

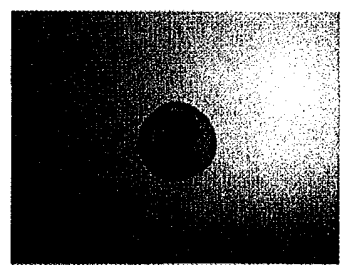

Moneda nabatea N. ${ }^{\circ} 2-17$

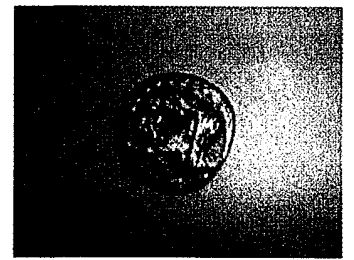

Moneda nabatea N. ${ }^{\circ} 2-12$

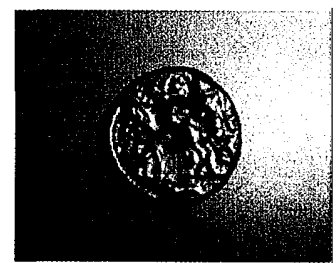

Moneda nabatea N. ${ }^{\circ} 2-14$ (1)

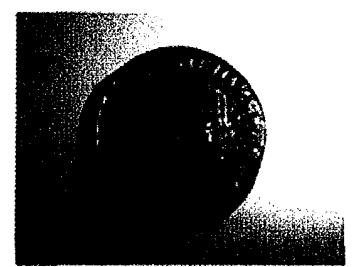

Moneda nabatea N. ${ }^{\circ} 2-16$

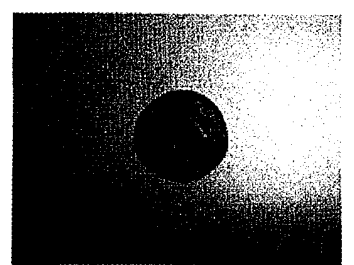

Moneda nabatea N. ${ }^{\circ}$ 2-17 (1) 


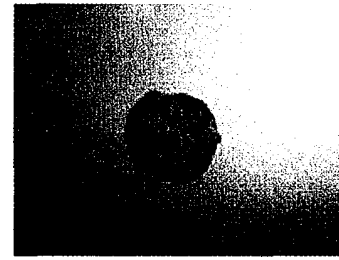

Moneda nabatea

N. ${ }^{\circ} 2-18$

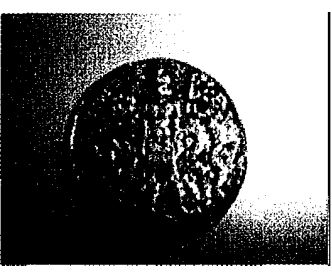

Moneda nabatea N. ${ }^{\circ} 2-29$ (1)

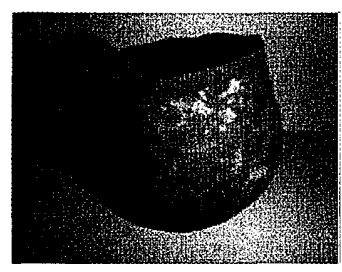

Taza nabatea con asa N. ${ }^{\circ} 2-28$

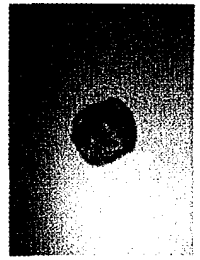

Moneda nabatea N. ${ }^{\circ} 2-18(1)$

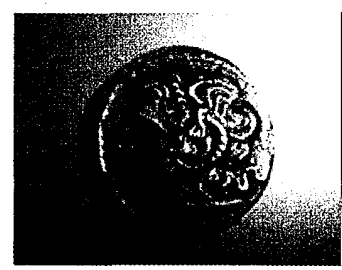

Moneda nabatea N. ${ }^{\circ} 2-30$

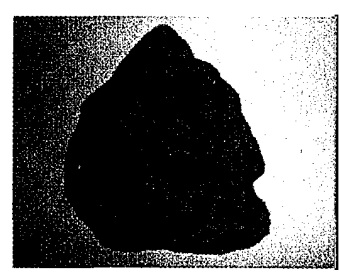

Terracota de Hermes N. ${ }^{\circ} 2-38$

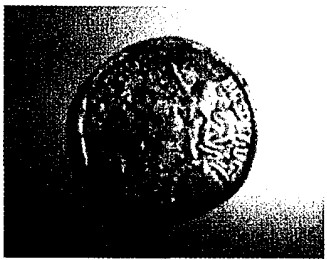

Moneda nabatea

N. ${ }^{\circ} 2-29$

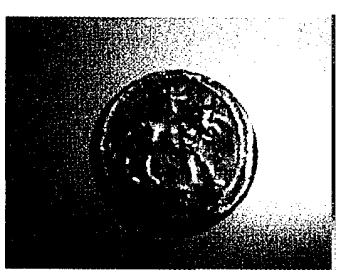

Moneda nabatea N. ${ }^{\circ}$ 2-30 (1) 